\title{
Are Bulk/Container Shipping Companies Improving Compared to the Baltic Dry Index?
}

\author{
Samuel D. Barrows ${ }^{1}$ \\ ${ }^{1}$ Bang College of Business, KIMEP University, Almaty, Kazakhstan \\ Correspondence: Samuel D. Barrows. E-mail: sam_barrows@yahoo.com
}

Received: October 24, 2019

Accepted: November 5, $2019 \quad$ Online Published: November 13, 2019

doi:10.5539/ass.v15n12p1

URL: https://doi.org/10.5539/ass.v15n12p1

\begin{abstract}
This study evaluates the 2000-2017 time frame and assesses the performance of the bulk/container shipping industry before and after the Great Financial Crisis (GFC) in relation to the Baltic Dry Index (BDI) and two other benchmarks in a variety of combinations. This study evaluates two different period portfolios of shipping companies based on their stock price total return performance. Five cases are presented that demonstrate portfolio improvement when comparing performance after the GFC with performance before the GFC in relation to the BDI and the other benchmarks. Included are discussions on shipping industry competition, vessel utilization and freight rates plus the BDI as an economic activity predictor.
\end{abstract}

Keywords: Bulk, Container Shipping, Baltic Dry Index

\section{Introduction}

Maritime transport, also known as shipping, is a well-established industry that utilizes routes where infrastructure along the routes is not normally needed. Only the end-points, or ports, and the ship itself as the carrying mechanism are required. Canals on most world routes are limited only to a very few locations. These features make "maritime transport highly economic" (Bistricic, 2007). Thus the major investments are typically the ships themselves.

The continuation of these investments leads to the overall development of the maritime business (Mrnjavac, 1998). The measure of how the shipping industry develops is based on the level of vessel usage (Neizvestnaya \& Mardanova, 2016). Shipping activities "represent the cheapest transportation of large amounts of goods" and is the framework for the majority of the "international exchange of goods" in the world economy (Bistricic, 2007). As a result, "the shipping industry is inextricably linked with the world economy", further "over $95 \%$ of world trade in volume terms moves by sea" (Kavussanos \& Marcoulis, 2005).

Shipping is a diverse industry with the individual ships varying greatly depending on the cargo focus and route logistics (Plomaritou, 2008). Configuring a shipping company's fleet to target customer needs allows for "commercial success of the enterprise" (Goulielmos, 2001). The shipping industry is divided into bulk and liner markets (Stopford, 2009). Bulk shipping companies "handle fewer, but much larger cargoes" and deal with fewer customers while liner operators handle many parcels, many times in containers, and deal with many customers (Kavussanos \& Marcoulis, 2005). Bulk carriers typically deal with raw materials while liner operators handle finished goods (Grama, 2012).

Normally, the supply of cargo ships is considered "inelastic" as it can take up to three years for ship construction and delivery, depending on vessel size and configuration (Geman \& Smith, 2012). However, there can be a small cross-utilization of vessels between the shipping markets "depending on the type and size of the ship, the type of goods and the transport distance" (Anechitoae, 2008). Certain cargo ships can handle multiple materials, and liner ships can accommodate customers not normally targeted. Also, tankers for crude oil and refined products "can be cleaned and refitted to transport dry bulk", although the alternative variant is not permitted because of the double hull requirement for tanker transport (Geman \& Smith, 2012).

For this study, tankers for crude oil and refined products are classified as a separate category. Technically, tankers are part of bulk shipping, but are not grouped together with bulk shipping per se, and are analyzed separately because of their commercial closeness to the oil industry. These tankers have an SIC code under the Energy sector as opposed to the Industrials sector which includes both the bulk and liner (container) operators 
(Thomson Reuters, 2018). Tankers also have their own specific indices targeting their usage (Baltic Exchange, 2018).

\section{Literature Review}

\subsection{Shipping Industry Competition}

There is a strategy where "shipping companies are active in both the bulk and liner markets and many ships, such as combined carriers and multipurpose vessels, are designed to operate in several different markets", and therefore allows for flexibility during changes in market dynamics (Plomaritou, 2008). In both the bulk and liner market segments, market concentration may influence pricing as well as vessel size, with larger vessels realizing a "lower profitability rate than smaller vessels" primarily due to an "oversupply of larger vessels" (Grama, 2014).

The shipping markets mirror the financial markets especially with regards to volatility (Qingcheng \& Chenrui, 2014). Demand factors include economic outlook, raw materials, finished goods, transportation costs, and political issues, whereas supply factors include size of the commercial feet, its renewal rate, and operational performance (Grigorut, 2012). In summary, the shipping markets can be said to be "seasonal, cyclical, and highly volatile" (Qingcheng \& Chenrui, 2014).

One study states that shipping industry returns "are positively affected by oil prices and the market value of equity are negatively affected by monthly industrial production" (Kavussanos \& Marcoulis, 2005). Due to inelastic supply scenarios, shipping companies temporarily "may generate excessive volatility in shipping costs, causing the index to deviate from the fundamentals of global trade and real economic activity" (Bakshi et al., 2010).

Companies in the shipping industry have various factors impacting their stock return performance. When viewed overall, in the global market, "maritime industry stocks do not carry above average market risk" (Kavussanos \& Marcoulis, 2005). The business cycle for the shipping industry is based on the demand for raw materials and includes four stages: peak, collapse, trough, and recovery, with a corresponding environment of stable periods surrounded by high volatility periods (Stopford, 2009).

\subsection{Vessel Utilization and Freight Rates}

The cost to use a ship is called the freight rate (Plomaritou, 2008). In general, it is based on straight supply and demand scenarios. In this case, it is the supply of the vessels available for use and the demand for the cargo being delivered (Grama, 2012). "If there are too many ships, the freight rate is low; while if there are too few ships, it will be high" (Plomaritou, 2008). If there is demand for the cargo transported, freight rates will be stable. (Bildirici et al., 2015). Vessel supply "is very inelastic" while demand for vessel usage "tends to be very elastic" (Papailias et al., 2017). As a result, configurations and markets served tend to focus "on the long-term trend" (Grama, 2012).

In the short term, ships can slow down their operation speed to save money if freight rates are low or there is a rise in bunker prices (Geman \& Smith, 2012). In the long term, investment decisions are based on the level of freight rates and vessel utilization (Plomaritou, 2008). When freight rates are high and/or when vessel utilization is high, investments are typically made "in new vessel capacity" (Grama, 2014).

Freight rates pricing "and volatility are related to the cycles in the world economy" plus demand for commodities as the cargo, and crude oil as the fuel, in addition to scrap prices for ship metal (Geman \& Smith, 2012). Freight rates can also be impacted by "the tightening of supply by carriers" (Grama, 2012). The opposite is also true. As vessel supply increases, freight rates tend to decrease (Stopford, 2009). When looking at long run indicators, "current vessel index" readings provide meaningful direction (Duru \& Yoshida, 2011). The use of these indices specifically related to freight rates "are used for extracting price inflation effects" (Duru et al., 2010).

\subsection{Baltic Dry Index}

The BDI is an often referenced index with regards to a variety of markets, from shipping itself, to commodities, manufacturing, financial markets, and general global economic activity. The Baltic Exchange as a collector and disseminator of this information was established in the eighteenth century (Geman \& Smith, 2012). Through the years, various indices have been established to quantify the maritime markets. In 1985, the Baltic Freight Index (BFI) was established "as a benchmark for the world freight market against which derivatives contracts would be financially settled" (Geman \& Smith, 2012). The BDI was introduced in 1999 to replace the BFI (Qingcheng \& Chenrui, 2014). The BDI "is the flagship today for dry bulk shipping costs" (Geman \& Smith, 2012). 
The BDI includes "the four largest dry-vessel classes" and is calculated as a weighted average (Bakshi et al., 2010). These include indices for the following: Capesize, Handysize, Panamax, and Supramax (Ko, 2011). These four classes include transportation of "iron, coal, cement, grain", metallic ores and other building materials (Oomen, 2012). The BDI uses the freight rates of over twenty maritime routes in its daily calculations to form the index and its cost structure is heavily dependent on crude oil prices and port fees (Bildirici et al., 2015). The BDI is never revised once it is published, and therefore is considered "largely devoid of speculative content" (Bakshi et al., 2010). Also, given the sheer number of vessels and players worldwide, the BDI would be "difficult to manipulate" (Bildirici et al., 2015).

\subsection{The BDI as a Predictor}

BDI use has expanded not only for vessel freight rates, but also for forecasting economic matters as it is linked to the demand for commodities, manufacturing, construction, and worldwide trade (Geman \& Smith, 2012). There is recognition that "the BDI growth rate predicts the growth in global economic activity, establishing further BDI's role in revealing a link between the real and financial sectors" (Bakshi et al., 2010). This forecasting applicability "is not only apparent on a short-term basis, but also it is persistent at longer horizons" (Apergis \& Payne, 2013). "The documented stock return predictability" adds credence as a predictor and as a result, the BDI can be used in a variety of markets (Bakshi et al., 2010).

Because of the supply and demand links, the BDI is often used to forecast the global economic picture (Bildirici et al., 2015). Moreover, because of this link to the global picture, the BDI "has the characteristics of a leading economic indicator" (Papilias et al., 2017). Movements in freight rates track differently from "stocks and bonds, but also from most commodities" and can have "volatility higher than $60 \%$ " due to the short term inelastic supply nature of vessels (Geman \& Smith, 2012).

With regard to the BDI and its use in other markets, "this volatility is harmful in the sense that their asset is exposed to high risk" (Ko, 2010). As a result, the "BDI occasionally over- or under-states the status of global dry bulk freight market" dynamics (Ko, 2011). In addition, since 2003, there is a general increase in volatility in the BDI, especially surrounding the GFC time frame (Ko, 2010). This volatility is more severe on the downside than on the upside (Chen \& Wang, 2004). There is also another dynamic present. "Freight rate volatility increases in a backwardated market and decreases when the market is in contango" (Ko, 2010).

As the BDI rises, increases in manufacturing and input materials are expected (Apergis and Payne, 2013). As one study succinctly states: "the BDI growth rate is positively related to the subsequent growth rate of industrial production, and the effect is statistically significant for most developed and emerging market countries" (Bakshi et al., 2010).

The BDI has become a proxy for economic behavior as an increase in the BDI "effects economic growth positively" (Bildirici et al., 2015). One study reviewing the 1985-2012 period "documents the joint predictability capacity of the BDI for both financial assets and industrial production", with its empirical findings that "demonstrate the robustness of the BDI's role in light of the presence of alternative indicators, the MSCI and oil prices" (Apergis \& Payne, 2013).

Another study finds "an increase in the BDI growth rate is associated with higher future stock returns" specifically, "the slope coefficient estimates are significant at the $5 \%$ level for eight out of the 11 regional indexes and G-7 markets" (Bakshi et al., 2010). This shows strong results for the majority of these markets. Also, the "predictability is corroborated in statistical terms, in-sample and out-of-sample, as well as through metrics of economic significance, and in the presence of some alternative predictors" (Bakshi et al., 2010).

A risk management analysis conducted using a 12-month forecast found "potential benefits of using sign-based timing for investing or hedging the BDI" (Papailias et al., 2017). Another study evaluating the time period 1988-2010 shows support for "the growth of the market of freight rates options, a safe hedging instrument for farmers and cooperatives that ship their grains to distant destinations" (Geman \& Smith, 2012).

\section{Methodology}

Stock price total return performance is a universally accepted method to gauge performance for individual companies and for portfolios of companies. Utilizing various benchmarks allow for multiple viewpoints with the various cases providing for a more complete understanding of the dynamics involved.

\subsection{Selection of Companies}

The data retrieval through Thomson Reuters provides total return format downloads for end of month readings. Sectors included in the study are from: Industrials / Transportation / Freight \& Logistics Services / Marine 
Freight and Logistics. Two subsectors are included in the analysis: Marine Freight \& Logistics (NEC) with 138 entries and Deep Sea Freight with 126 entries. Inland Water Freight is not included as this category is more impacted by local parameters as opposed to global factors.

Total companies posting data in the initial month of January 2000 is 90 with the total companies posting data in the final month of December 2017 is 226 . Not all companies posted results throughout the entire period as some were not listed initially or were subsequently delisted. Further study restrictions on portfolio companies include the requirement for company annual revenues exceeding $\$ 300$ million in 2017. This reduces the portfolios to 60 companies. The Sea-Borne Tankers segment as part of the Energy sector is not included as the dynamics are somewhat different due to the nature of the crude oil and refined products markets.

\subsection{Creation of Portfolios}

To evaluate the performance of the portfolios during the eighteen-year study time frame, two different period portfolios are created. The first period is 2000-2008 and the second period is 2009-2017. Each period is nine years in duration with the GFC as the dividing line. For purposes here, the GFC is assumed to begin during September 2008 with the Lehman Brothers collapse (Haas \& Van Horen, 2012). The Dow Jones closing low point during the GFC is on March 5, 2009, with a decline of 53\% from its peak on October 9, 2007, and for the purposes of this study, this date represents the turning point toward recovery in the GFC (Amadeo, 2018).

A set of summary statistics details the results of the cases. For the individual cases, a two-sample test serves as the assessment for the two time periods. A two-sample test is conducted to examine the differences between the two time periods and their interactions to the benchmarks (Penn State, 2007). The two-sample test is constructed using a Short Long portfolio. The cases use the Short Long portfolio methodology to distinguish performance between the 2000-2008 period and the 2009-2017 period.

The Short Long portfolio methodology combines two different time periods using a short strategy or "selling" in one time period and a long strategy or "buying" in another time period. For the purposes in this study, the Short Long portfolio is selling for the 2000-2008 period and buying for the 2009-2017 period. A similar study was conducted on merger performance in the oil industry where two different time periods were evaluated to ascertain which period had superior performance (Barrows, 2018).

\subsection{Utilization of Benchmarks}

To evaluate the two portfolios, their performance against various benchmarks allow for a more detailed and realistic comparison between the two periods. A simple appraisal of the two portfolios may not provide a meaningful assessment between the periods as the influences of the various factors on them could greatly influence performance within the two periods. To allow more relevant comparisons, three benchmarks are included in this analysis: the BDI from the Baltic Exchange (Baltic Exchange, 2018); the CRSP Global market and the CRSP Transport industry retrieval from 49 industries, both from the Center for Research in Securities Prices (Dartmouth, 2018). All three benchmarks exclude the risk free rate, which is deemed as the US one month Treasury-bill rate.

\subsection{Analytical Cases}

The research question is the following: Are Bulk/Container Shipping Companies improving compared to the Baltic Dry Index? The objective of this study is to evaluate the stock market returns between the two nine-year portfolios. The stock price total return of the portfolios is the dependent variable in this analysis. The independent variables are the three benchmarks. The basis of the research is classified as causal and correlational. The intent is to determine if there is a causal connection then quantify the relationship of the stock price total return performance of the portfolios to the various benchmarks. To further explore this topic and focus on quantifying the research question, two hypotheses are considered.

H1: The 2009-2017 period is superior to the 2000-2008 period in a majority of the three-factor tests.

H2: The 2009-2017 period is superior to the 2000-2008 period in a majority of the two-factor tests.

The period portfolios are compared to the benchmarks and utilize a version of the Fama and French three-factor model and a more basic two-factor model (Fama \& French, 1993). The intent is to evaluate the long-run abnormal returns of the portfolios less the long-run returns of the various benchmarks (Barber \& Lyon, 1997). The formulas used in the analysis are included below with the RF Rate representing the risk free rate.

\section{Three-Factor Tests:}

$$
\text { Portfolio }-R F \text { Rate }=\alpha+\beta(B D I-R F \text { Rate })+\beta((\text { Global Market or Transport Industry })-\text { RF Rate })
$$


Two-Factor Tests:

$$
\text { Portfolio }-R F \text { Rate }=\alpha+\beta((B D I \text { or Global Market or Transport Industry })-\text { RF Rate })
$$

This analytical approach utilizes five cases which examine the stock price total return monthly percent changes for the two portfolios. The first two cases use the three-factor model each with two of the benchmarks. The last three cases use the two-factor model each with only one of the benchmarks. For more information, please see the Table 1 below.

Table 1. Comparison of Cases

\begin{tabular}{cccc}
\hline Short / Long Portfolio Cases & Baltic Dry Index & Global Market & Transport Industry \\
\hline Short 2000-2008 / Long 2009-2017 & $\mathrm{X}$ & $\mathrm{X}$ & $\mathrm{X}$ \\
Short 2000-2008 / Long 2009-2017 & $\mathrm{X}$ & & \\
Short 2000-2008 / Long 2009-2017 & $\mathrm{X}$ & $\mathrm{X}$ & $\mathrm{X}$ \\
Short 2000-2008 / Long 2009-2017 & & & \\
Short 2000-2008 / Long 2009-2017 & & & \\
\hline
\end{tabular}

\section{Results and Discussion}

In the Table 2 Comparison of Results, the first measurement displayed is the Y-Intercept. For the scenario purposes in this study, the Y-Intercept equates to alpha. If alpha is positive in the Short Long scenario then the Long portfolio (the 2009-2017 period) is the superior performer. If alpha is negative then the Short portfolio (the 2000-2008 period) is the superior performer. The summary results of the cases analyzed are included in Table 2 below. The detailed comparisons are discussed below the table.

Table 2. Comparison of Results

\begin{tabular}{|c|c|c|c|c|c|}
\hline $\begin{array}{c}\text { Results } \\
*=10 \%, * *=5 \%, * * *=1 \% \\
\text { denote significance levels }\end{array}$ & $\begin{array}{c}\text { Alpha } \\
\text { (Y Intercept) }\end{array}$ & t-stat & $\begin{array}{l}\text { Beta } \\
\text { One }\end{array}$ & $\begin{array}{l}\text { Beta } \\
\text { Two }\end{array}$ & $\begin{array}{l}\text { Adj } \\
\text { R2 }\end{array}$ \\
\hline 1. BDI + Global Market & $1.00 * * *$ & 5.92 & $1.10 * * *$ & $2.78 * * *$ & 0.47 \\
\hline 2. BDI + Transport Industry & $0.28 * * *$ & 3.43 & $0.79 * * *$ & $1.71 * * *$ & 0.87 \\
\hline 3. BDI & $1.60 * * *$ & 10.90 & $1.21 * * *$ & & 0.38 \\
\hline 4. Global Market & 0.06 & 0.34 & $3.70 * * *$ & & 0.17 \\
\hline 5. Transport Industry & $(0.44) * * *$ & $(4.44)$ & $1.98 * * *$ & & 0.72 \\
\hline
\end{tabular}

The alphas ( $\mathrm{Y}$ intercepts) are positive for cases 1, 2, 3, and 4. These results have the 2009-2017 period as superior to the 2000-2008 period. The only negative alpha is case 5, which has the 2000-2008 period as superior to the 2009-2017 period. Thus, four out of the five cases have the 2009-2017 period as superior to 2000-2008 period.

When comparing the results using the single benchmarks in cases 3, 4, and 5, the performance of the 2009-2017 period is the highest on a relative basis over the 2000-2008 period in case 3 using BDI as the benchmark in comparison to the other benchmarks with the second place reading in case 4 using the global market as the benchmark.

The P-value measurements for the alphas (Y intercept) for four out of the five cases are all at a $1 \%$ level which indicate the acceptance of the null hypotheses in a statistically significant manner. Only case 4 is not at a statistically significant level.

With regard to the Adjusted R Squared readings, cases 1 and 2 referencing two benchmarks have Adjusted R Squared readings at 0.47 , and 0.87 , respectively. Cases 3,4 , and 5 are compared to only one benchmark, and the Adjusted R Squared readings are at $0.38,0.17$, and 0.72 , respectively. Both cases 2 and 5 include the transport industry in the benchmarks and have elevated Adjusted R Squared readings illustrating the high correlation between the shipping companies and the transport industry.

With regard to the first hypothesis considered, H1: The 2009-2017 period is superior to the 2000-2008 period in a majority of the three-factor tests, the results confirm that the 2009-2017 period performs superior to the 2000-2008 period in a statistically significant manner in both of the cases 1 and 2 . These results confirm the H1 null hypothesis. The 2009-2017 period is superior to the 2000-2008 period in both of the two cases of the three-factor tests.

With regard to the second hypothesis considered, H2: The 2009-2017 period is superior to the 2000-2008 period 
in a majority of the two-factor tests, the results confirm that the 2009-2017 period performs superior to the 2000-2008 period in a statistically significant manner in cases 3 and 4, but not 5 . These results confirm the H2 null hypothesis. The 2009-2017 period is superior to the 2000-2008 period in two out of the three cases of the two-factor tests.

These results coincide with research that documents a proven link between the BDI and economic activity. BDI "has the characteristics of a leading economic indicator" (Papilias et al., 2017). Furthermore, in both developed and emerging economies, "the BDI growth rate is positively related to the subsequent growth rate of industrial production" (Bakshi et al., 2010). As a proxy, a BDI increase "effects economic growth positively" (Bildirici et al., 2015).

In summary, "an increase in the BDI growth rate is associated with higher future stock returns" (Bakshi et al., 2010). This dynamic is also present when utilizing alternative benchmarks (Bakshi et al., 2010; Apergis \& Payne, 2013). This allows for more utilization of the BDI as a predictor. Moreover, this forecasting applicability "is not only apparent on a short-term basis, but also it is persistent at longer horizons" (Apergis \& Payne, 2013). With that said, the "BDI occasionally over- or under-states the status of global dry bulk freight market" dynamics (Ko, 2011).

\section{Conclusion}

The research question is: Are Bulk/Container Shipping Companies improving compared to the Baltic Dry Index? Using the methodology in this study and the significance of the measurements, the hypothesis is confirmed using the included case scenarios. Bulk/container shipping stock market returns are indeed improving compared to the Baltic Dry Index.

It is interesting to note that when the Short Long portfolios are compared to the single benchmarks, the highest reading is at the BDI comparison. This shows that the 2009-2017 period indeed improves over the 2000-2008 period using BDI as a scorecard in the clearest manner, while the other benchmark combinations also give an almost unanimous support for this dynamic.

Given that the BDI is a link to commodities demand and manufacturing levels, this should not be a surprise since at the beginning of the 2009-2017 period, right after the GFC, economic and market levels around the world were extremely depressed so they were likely to gain tremendously during the 2009-2017 period. Also, the risk free rate during part of this time was at zero percent which would help fuel the growth in most sectors of the world economy.

\section{References}

Amadeo, K. (2018, October 14). 2009 Financial Crisis Explanation with Timeline How They Stopped the Madness. The Balance. Retrieved from https://www.thebalance.com/2009-financial-crisis-bailouts-3305539

Anechitoae, C. (2008). Maritime Systems Geopolitics. Bucharest: Military Publishing House.

Apergis, N., \& Payne, J. E. (2013). New evidence on the information and predictive content of the Baltic Dry Index. International Journal of Financial Studies, 1(3), 62-80. https://doi.org/10.3390/ijfs1030062

Bakshi, G. S., Panayotov, G., \& Skoulakis, G. (2010). The Baltic Dry Index as a Predictor of Global Stock Returns, Commodity Returns, and Global Economic Activity. https://doi.org/10.2139/ssrn.1747345

Baltic Exchange. (2018). Retrieved November 21, 2018, from https://balticexchange.com

Barber, B., \& Lyon, J. (1997). Detecting long-run abnormal stock returns: The empirical power and specification of test statistics. J. of Financial Economics, 43, 341-372. https://doi.org/10.1016/S0304-405X(96)00890-2

Barrows, S. D. (2018). Are Oil Industry Mergers Becoming Less Profitable? International Journal of Energy Economics \& Policy, 8(2), 31-38. Retrieved from http://econjournals.com/index.php/ijeep/article/view/5484

Bildirici, M. E., Kayikci, F., \& Onat, I. S. (2015). Baltic Dry Index as a Major Economic Policy Indicator: The Relationship with Economic Growth. Procedia - Social and Behavioral Sciences, 210, 416-424. https://doi.org/10.1016/j.sbspro.2015.11.389

Bistricic, A. (2007). Shipbuilding Projects from a Shipyard's Perspective and the Role of the Bank in the Project Lifetime Management. Journal of Contemporary Management Issues, 12(1), 101.

Chen, Y., \& Wang, S. (2004). The Empirical Evidence of the Leverage Effect on Volatility in International Bulk $\begin{array}{lllll}\text { Shipping Market. Maritime Economics \& Logistics, } & 31(2), & \text { 109-124. }\end{array}$ https://doi.org/10.1080/0308883042000208301 
Dartmouth. (2018). Changes in CRSP Data are provided by http://mba.tuck.dartmouth.edu/pages/faculty/ken.french/data_library.html\#Research

Duru, O., \& Yoshida, S., (2011). Long Term Freight Market Index and Inferences. The Asian Journal of Shipping and Logistics, 27(3), 405-422. https://doi.org/10.1016/S2092-5212(11)80019-2

Duru, O., Bulut, E., \& Yoshida, S. (2010). Bivariate long term fuzzy time series forecasting of dry cargo freight

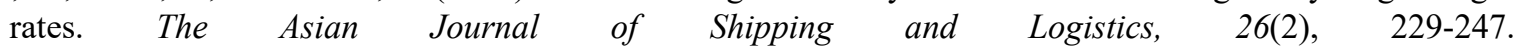
https://doi.org/10.1016/S2092-5212(10)80002-1

Fama, E., \& French, K. (1993). Common risk factors in returns on stocks and bonds. Journal of Financial Economics, 33, 3-56. https://doi.org/10.1016/0304-405X(93)90023-5

Geman, H., \& Smith, W. O. (2012). Shipping markets and freight rates: an analysis of the Baltic Dry Index. Journal of Alternative Investments, 15(1), 98-109. https://doi.org/10.3905/jai.2012.15.1.098

Goulielmos, A. (2001). Operational Management of Shipping Companies. Athens: Stamoulis Publications.

Grama, I. G. (2012). The Influence of the Global Economic Crisis on the Evolution of Liner Shipping Market. Economics, Management and Financial Markets, 7(4), 632.

Grama, I. G. (2014). The Importance of Reducing Freight Rates and Maritime Transport Costs. Economics Management and Financial Markets, 9(1), 292.

Grigorut, C. (2012). The Freight Market. Contemporary Readings in Law and Social Justice, 4(2), 889.

Haas, R. D., \& Van Horen, N. (2012). International Shock Transmission after the Lehman Brothers Collapse: Evidence from Syndicated Lending. American Economic Review, 102(3), 231-237, https://doi.org/10.1257/aer.102.3.231

Kavussanos, M. G., \& Marcoulis, S. N. (2005). Shipping Economics. Research in Transportation Economics, 12, 107-142. https://doi.org/10.1016/S0739-8859(04)12004-0

Ko, B. W. (2010). A Mixed-Regime Model for Dry Bulk Freight Market. The Asian Journal of Shipping and Logistics, 26(2), 185-204. https://doi.org/10.1016/S2092-5212(10)80001-X

Ko, B. W. (2011). Dynamics of Dry Bulk Freight Market: Though the Lens of a Common Stochastic Trend Model. The Asian Journal of Shipping and Logistics, 27(3), 387-404. https://doi.org/10.1016/S2092-5212(11)80018-0

Mrnjavac, E. (1998). Pomorski sustav, Rijeka, Faculty of maritime studies.

Neizvestnaya, D. V., \& Mardanova, A. R. (2016). The Technique of the Factorial Analysis of the Profitability of the Segments in Waterborn Transport Companies. J. of Economics \& Economic Edu. Research, 17, 406.

Oomen, J. (2012). The Baltic Dry Index: A predictor of stock market returns? (Master Thesis) Tilburg University.

Papailias, F., Thomakos, D. D., \& Liu, J. (2017). The Baltic Dry Index: cyclicalities, forecasting and hedging strategies. Empirical Economics, 52(1), 255-282. https://doi.org/10.1007/s00181-016-1081-9

Penn State. (2007). Retrieved November 13, 2018, from http://psu.edu/ ajw13/stat200_notes/10_twogroups/ 08_twogroups_print.html

Plomaritou, E. I. (2008). A Proposed Application of the Marketing Mix Concept to Tramp \& Liner Shipping Companies. Journal of Contemporary Management Issues, 13(1), 59.

Qingcheng, Z., \& Chenrui, Q. (2014). An approach for Baltic Dry Index analysis based on empirical mode decomposition. Maritime Policy \& Manag., 4l(3), 224-240. https://doi.org/10.1080/03088839.2013.839512

Stopford, M. (2009). Maritime Economics. London: Routledge. https://doi.org/10.4324/9780203891742

Thomson Reuters. (2018). Thomson Reuters Eikon product. Retrieved from https://thomsonreuters.com/en/ products-services/financial/trading-platforms/thomson-reuters-eikon.html

\section{Copyrights}

Copyright for this article is retained by the author(s), with first publication rights granted to the journal.

This is an open-access article distributed under the terms and conditions of the Creative Commons Attribution license (http://creativecommons.org/licenses/by/4.0/). 